\title{
Meta
}

Journal des traducteurs

Translators' Journal

\section{“Creative Shifts” as a Means of Measuring and Promoting Translational Creativity}

\section{Gerrit Bayer-Hohenwarter}

Volume 56, numéro 3, septembre 2011

URI : https://id.erudit.org/iderudit/1008339ar

DOI : https://doi.org/10.7202/1008339ar

Aller au sommaire du numéro

\section{Éditeur(s)}

Les Presses de l’Université de Montréal

\section{ISSN}

0026-0452 (imprimé)

1492-1421 (numérique)

Découvrir la revue

Citer cet article

Bayer-Hohenwarter, G. (2011). “Creative Shifts” as a Means of Measuring and Promoting Translational Creativity. Meta, 56(3), 663-692.

https://doi.org/10.7202/1008339ar

\section{Résumé de l'article}

Grâce à l'oeuvre de Paul Kuß̧maul, la recherche sur la créativité en traduction a fait de grands progrès. Mesurer la créativité en traduction demeure cependant un défi à relever. Le présent article fait état des résultats d'une étude portant sur l'analyse d'un aspect de la créativité considéré comme essentiel. Cet aspect, nommé déplacement créateur, permet de mesurer la capacité du traducteur à s'éloigner de la structure du texte de départ. Un déplacement créatif peut apparaître sous diverses formes, telles qu'une abstraction ou une modification, ou encore une concrétisation dans le texte cible par rapport au texte de départ. Nous présentons une analyse de 16 unités textuelles provenant de 4 textes expérimentaux, qui ont été traduites, chacune, par 11 étudiants en traduction et 5 traducteurs professionnels. Le but de l'analyse est de mesurer la flexibilité du traducteur, entendue comme étant la capacité à s'éloigner de la structure linguistique du texte de départ, au lieu de réaliser de simples reproductions littérales. Les résultats révèlent de nettes différences entre les étudiants et les traducteurs professionnels et permettent d'établir des tendances en rapport avec le développement de la compétence créative en traduction. En outre, non seulement ils ouvrent une piste nouvelle pour l'analyse de phénomènes cognitifs complexes, mais ils représentent également un point de départ prometteur pour la recherche et l'application pédagogiques.
Ce document est protégé par la loi sur le droit d'auteur. L’utilisation des services d'Érudit (y compris la reproduction) est assujettie à sa politique d'utilisation que vous pouvez consulter en ligne.

https://apropos.erudit.org/fr/usagers/politique-dutilisation/ 


\title{
ÉTUDES ET PROSPECTIVES
}

\section{"Creative Shifts" as a Means of Measuring and Promoting Translational Creativity}

\author{
GERRIT BAYER-HOHENWARTER \\ Universität Graz*, Graz, Austria \\ ger1676@yahoo.com
}

\section{RÉSUMÉ}

Grâce à l'œuvre de Paul Kußmaul, la recherche sur la créativité en traduction a fait de grands progrès. Mesurer la créativité en traduction demeure cependant un défi à relever. Le présent article fait état des résultats d'une étude portant sur l'analyse d'un aspect de la créativité considéré comme essentiel. Cet aspect, nommé déplacement créateur, permet de mesurer la capacité du traducteur à s'éloigner de la structure du texte de départ. Un déplacement créatif peut apparaître sous diverses formes, telles qu'une abstraction ou une modification, ou encore une concrétisation dans le texte cible par rapport au texte de départ. Nous présentons une analyse de 16 unités textuelles provenant de 4 textes expérimentaux, qui ont été traduites, chacune, par 11 étudiants en traduction et 5 traducteurs professionnels. Le but de l'analyse est de mesurer la flexibilité du traducteur, entendue comme étant la capacité à s'éloigner de la structure linguistique du texte de départ, au lieu de réaliser de simples reproductions littérales. Les résultats révèlent de nettes différences entre les étudiants et les traducteurs professionnels et permettent d'établir des tendances en rapport avec le développement de la compétence créative en traduction. En outre, non seulement ils ouvrent une piste nouvelle pour l'analyse de phénomènes cognitifs complexes, mais ils représentent également un point de départ prometteur pour la recherche et l'application pédagogiques.

\section{ABSTRACT}

Thanks to Paul Kußmaul, the investigation of translational creativity has made considerable progress. The measurement of creativity, however, has remained a great challenge. The following article presents the results of the measurement of one aspect considered central to the notion of translational creativity, namely the measurement of the ability to depart from the source text (ST) structure by applying creative shifts, i.e., abstracting, modifying or concretising source text ideas in the target text (TT). Sixteen units of analysis from 4 experimental texts translated by 11 students of translation and 5 professional translators each were analysed with the aim of finding out how many of them constituted creative shifts as opposed to mere reproductions of the source text. The results of this sample analysis reveal that there are clear differences between student and professional behaviour and that a certain trend for the development of creative competence can be established. Moreover, these results do not only point to a methodologically interesting approach for analysing complex cognitive constructs, but they also provide a valuable starting point for pedagogic research and application.

\section{MOTS-CLÉS/KEYWORDS}

créativité en traduction, déplacement créatif, reproduction littérale, développement de compétence, processus de traduction

translational creativity, creative shift, literal reproduction, competence development, translation process 


\section{Background}

The various conceptions and definitions of creativity that can be found in the psychological literature on creativity research and in translation research are so multifaceted that any attempt to describe its complexity in an exhaustive manner and provide the definition of translational creativity is bound to fail. A general consensus in psychological creativity research that was taken up in the field of translation is, however, that truly creative work is "novel" and "acceptable" (e.g., Kußmaul 2007a; Dancette, Audet et al. 2007). Moreover, a number of important steps have been accomplished in translation research to conceptualise, i.e., identify and characterise translational creativity. For this reason, a brief but not exhaustive overview of the state and development of translational creativity research is now given. More specific work on related aspects such as inspiration, intuition or incubation is beyond the scope of this article.

\subsection{Translational creativity research in a nutshell}

Whereas the psychological discipline of creativity research saw its birth in 1950, creativity in translation research has long remained confined to "rather marginal comments" (Wilss 1988: 110; my translation) and, until the 1990s, it had been discussed predominantly within the literal-versus-free-debate. According to Wilss, the reason was that translational creativity could "neither be clearly conceptualized, nor measured, nor weighted nor described precisely” (Wilss 1988: 111, my translation).

The first empirical study is, to my knowledge, Wilde's (1994) type/token analysis conceived to analyse the relation between Language for Specific Purposes (LSP) elements such as light-verb constructions ${ }^{1}$ and creative elements in promotional texts. In her study that was extremely progressive for its time, Wilde found that even LSPspecific syntactic structures can work as creative elements (Wilde 1994: 25). Also in the 1990s, Kußmaul ventured to undertake a large-scale series of investigations into translational creativity based on observation and empirical data from the translation classroom. His groundbreaking work (Kußmaul 1991; 1993; 1997; 1998; 1999; 2000a; 2000b; 2000c; 2004; 2005; 2007a; 2007b) impressively demonstrates the value that cognitive and psychological insights can have for translation research and practice and for translator training.

Apart from Kußmaul's seminal work, research into translational creativity has been of limited scope. Studies were carried out frequently with regard to specific text types, e.g., promotional texts (Quillard 1998; 2001; Jettmarovà 1998), religious texts (Nida 1998; Nord 2005), audiovisual translation (Fontcuberta Gel 1997; Chaume Varela 1998), popular music (Kaindl 2005), technical texts (Durieux 1991; Schmitt 2005; Byrne 2006) and legal texts (Nida 1998; Šarčević 2000; Pommer 2008). Other investigations have dealt with pedagogic aspects (Mackenzie 1998; Lee-Jahnke 2005; Forstner 2005; Bastin 2000; 2003). Dancette, Audet et al. (2007) developed criteria for translational creativity, Hubscher-Davidson $(2005 ; 2006)$ and Hague (2009) place the focus of their research on the creative personality of translators. Thomä (2003) created a translation-specific creativity test and analysed the creativity of 30 students in their first or second semester of studies in English Language and Literature with that of 16 professional translators in her PhD thesis. Al-Shabab (1996), Kenny (2000; 
2001; 2006), and Laviosa (1998) compared the degree of creativity inherent in source texts and target texts and observed a trend towards less original and more conventional target texts that Stewart (2000) attributes to the use of corpora by translators. A first conference on translation and creativity was held on $12^{\text {th }}$ November 2005 in Portsmouth (Kemble and O'Sullivan 2006) and brought practising translators, researchers and translation teachers together. The diversity of the contributions to this conference clearly illustrates the diversity of the perspectives on the subject.

In translation process research, Heiden (2005) carried out an investigation from a key-logging study and found that most creative translations are first created in the main phase and that long revision phases are a strong indication for creative translation processes. Fontanet (2005) conducts self-experiments with technical texts that are described using psychological concepts (incubation, illumination etc.) and finds that the problem-solving processes use divergent thinking differently for comprehension problems and production problems. Audet (2008) reports on a framework for the analysis of translational creativity that was developed following the analysis of think-aloud data of translation processes. This framework resembles text-analytic approaches and allows for qualitative creativity assessment. Other process-oriented studies were carried out by Kußmaul (2007a); Hubscher-Davidson (2005; 2006); and Cho (2006).

Methodologically speaking, the large number of studies on aspects of limited scope and conceptualization issues has paved the way for quantitative research. The focus of interest is now on research that measures translational creativity or is useful for its measurement. To this date, the more relevant approaches are large-scale empirical investigations that extend beyond sample text analyses and the discussion of conceptualisation issues. This refers to research such as Adamczuk (2005) or the corpus-linguistic studies by Al-Shabab (1996); Kenny (2000; 2001; 2006); Laviosa (1998); and Stewart (2000). The most relevant approaches, in my view, are studies using psycholinguistic methods such as key-logging or think-aloud as carried out by Kußmaul (2007a); Fontanet (2005); Heiden (2005); Hubscher-Davidson (2005; 2006); Cho (2006); Audet and Dancette (2005); Dancette, Audet et al. (2007); and Audet (2008). Such studies allow penetrating even deeper levels of analysis.

The following two sections now concentrate on empirical findings about two aspects that are particularly relevant for the present analysis. The first is the relationship between creativity and expertise, which is relevant for an investigation into the development of translation competence in the expert-novice paradigm. The second important aspect is about cognitive shifts, because these can be considered as one important manifestation of translational creativity.

\subsection{Translational creativity and expertise}

As far as connections between creativity and expertise are concerned, little research evidence exists. Thomä (2003: 224) found that creativity, as rated by three experts, was higher in professionals than in students, and higher in translations into the mother tongue than into a foreign language. In addition, professionals apparently were more original than students, and translations into the foreign language more original than those into the mother tongue, regardless of the competence level (Thomä 2003: 213). The fact that translations into the mother tongue were rated as 
more creative but that they were less original on average was not commented on explicitly by Thomä. "Fluency" (commonly defined as the ability to produce "a large number of ideas per unit of time" in creativity psychology according to Guilford 1950: 452) and "flexibility" (i.e., the ability "to change set"; Guilford 1950: 452) were largely independent of both expertise and language direction (Thomä 2003: 235). Because of certain methodological shortcomings, these results must, however, be interpreted with some caution.

Another investigation linked to creativity and expertise is a think-aloud study (Japanese/Korean) carried out by Cho (2006). Among others, she seeks to find out about the relation between creativity and translation quality. In an analysis of 20 source text (ST) sentences comprising 196 words translated by 13 translators, she finds that the number of shifts produced by the translators was between $0 \%$ and $30 \%$. She draws the conclusion that, as a result of the syntactic similarities between Japanese and Korean, the translators are tempted to translate literally and hence uncreatively. This causes the target text quality to suffer from undetected inferences.

Apart from Thomä (2003) and Cho (2006), Riccardi (1998) reports on a series of strategies characteristic of novices and experts that she observed with interpreters. Even if she did not provide empirical evidence for her postulates, they seem compatible with existing research from the field of expertise and with my own hypotheses. Riccardi states that, among other differences, experts have a broader inventory of strategies than novices and are able to combine these strategies in a more flexible way. In this respect, experts are more creative text producers than novices.

The research most relevant to the present investigation was carried out by Bastin and Betancourt (2005). They carried out a classroom experiment where 25 students in their first semester translated one text on their first day of studies and a second after 15 weeks of translator training. The translations were from English (L2) into French (L1). The researchers analyzed the quality of the target texts and their creativity in terms of shifts. The shifts were defined as paraphrases and new creations (my translation) as opposed to literal translation (Bastin and Betancourt 2005: 218). Paraphrases refer to all cases where deviations from literal translations are made by a translator in order to preserve the idiomaticity of the target text. New creations refer to all cases where the translator makes more extensive changes, for example, by changing grammatical categories, restructuring or adapting the text. They found that the quality of the second translation improved, the number of paraphrases increased by $25 \%$ and the number of adaptations by more than $100 \%$ but the number of literal translations only decreased by $6 \%$. These seemingly incongruent results can be explained by the fact that all erroneous translations (except grammatical or orthographic errors) were disregarded. However, if the first translation was erroneous and the second of the same participant was correct, the second translation was counted all the same. As the authors acknowledge (2005: 219), this approach had a considerable impact on the results and is disputable. Nevertheless the authors conclude (Bastin and Betancourt 2005: 221): "[1] a conclusion à en tirer est que bien évidemment 45 heures de méthodologie de la traduction ne suffisent pas pour faire acquérir à l'étudiant moyen les réflexes traductionnels indispensables" (“45 hours of training in translation methodology are insufficient in order for students to learn the indispensable translational reflexes," [my translation]), or in other words perhaps, to unlearn the reflex of literalness. 


\subsection{Translational creativity and cognitive shifts}

After centuries and decades of literal-versus-free discussion, it is beyond dispute that translating involves the production of non-literal target texts that can still be perfectly skopos-adequate and that skopos adequacy sometimes even necessitates non-literalness, i.e., shifts that depart from the ST wording but not from the ST meaning, hence "cognitive shifts."

Along these lines, Jones (2006) considers those strategies that lead to target text (TT) elements reflecting the nature of the ST without reproducing its linguistic structure as creative. Ballard (1997), Ivir (1998) and Pellatt (2006) define such creative procedures in line with de Beaugrande (1978: 3) and his structuralist transformation mechanisms. For Ivir (1998: 137), such procedures comprise borrowing, literal translation, definition, substitution, lexical creation, addition, and omission, whereby he defines the translator's creativity as "his/her ability to choose a strategy that will suit the context of situation in which the translational situation takes place" (Ivir 1998: 144). Pellatt (2006: 52) uses addition, substitution, permutation, reduction as opposed to the non-creative use of 'ordinary' language as indicators of creativity. For Ballard (1997: 90), the most important procedures, which even go back to Cicero, are "addition" and "omission." More precisely, however, he speaks of shifts in hyperonymic or hyponymic relations and changes in the degree of explicitness and searches for the triggers of such changes (e.g., register, polysemy, euphony). Another categorization, undertaken by Bastin and Betancourt (2005: 219), comprises paraphrases and new creations (périphrase and recréation), considered as creative procedures) as opposed to non-creative literal versions.

On a cognitive level of analysis, Kußmaul (2007a: 31) introduces the concept of obligatory shifts (that also entails the existence of "optional shifts") and develops his types of creative translation, which is a first typology of cognitive shifts based on scenes-and-frames theory (2000b; 2000c; see Bayer-Hohenwarter 2009 for a more detailed discussion).

In contrast to shifts, literal translation is, according to Ballard (1997: 90), "l'idéal conscient ou inconscient de l'équivalence est le littéralisme" ("the conscious or unconscious ideal of equivalence"; my translation). This assumption is also supported by observations from Englund Dimitrova (2005) and empirical evidence from Zhong (2005) and Tirkkonen-Condit, Mäkisalo et al. (2008). Here, all authors seem to adhere to the general consensus that what I call "the literal translation reflex" is presumably a cognitive universal, but certainly not a universally valid, acceptable and accepted quality standard.

\subsection{Empirical results on translational creativity in a nutshell}

Regarding the results of empirical studies on translational creativity, there are few results that seem to be based on sound empirical evidence:

1) Divergent thinking is useless without sufficiently developed evaluation competence (Kußmaul 1991; Bastin 2003);

2) Across various text types, there are strong normalisation trends in translations into English, whereas the opposite trend was observed for translations of promotional texts into French (Al-Shabab 1996; Kenny 2000; 2001; 2006; Laviosa 1998; Stewart 2000; Quillard 1998; 2001); 
3) Metaphorisation is an important creative translation strategy (Adamczuk 2005);

4) ST metaphors in non-literary texts that are highly conventionalised usually are preserved by translators in the TT (Pisarska 1989);

5) No substantial decrease in the use of literal translations can be expected from students at the beginning of their second semester and from those who were trained in translation methods for one semester (Bastin and Betancourt 2005).

By way of conclusion, the evidence presented in this section shows that research into translational creativity has so far covered a broad range of individual aspects and has made considerable progress in conceptual issues, but that, until now, no study has devised a comprehensive creativity assessment procedure. Only the study carried out by Bastin and Betancourt (2005) measured creativity according to strict criteria and ventured to analyse the development of translational creativity, even if this was only done at the beginning and towards the end of one semester of translator training.

\subsection{Translational creativity within TransComp}

Research aimed at a more comprehensive view and operationalisation of creativity has only recently been undertaken. Within TransComp (Göpferich, Bayer-Hohenwarter et al. 2011; Göpferich 2009), a comprehensive framework (see Bayer-Hohenwarter 2009) and a sophisticated creativity assessment procedure (see Bayer-Hohenwarter 2010) have been developed for the analysis of translational creativity. Criteria were devised to measure creativity quantitatively across different units of analysis (= chunks of text), and across different experimental texts, regardless of their text type. This measurement is carried out on a product level and on a process level of analysis using think-aloud data and Translog data. The TransComp corpus of data and my creativity assessment procedure eventually make it possible to compare the creative performance of different translators, such as students in different semesters (first to sixth) with professionals, and trace the development of their performance in time.

This creativity assessment procedure was designed in order to test several assumptions relevant for translation pedagogy, some of which can also be tested within the present study. Above all, I was curious to know if translators who showed more signs of creative thinking by producing more abstractions, concretisations or changes of perspective when producing target texts would also achieve a higher overall performance. If this proved to be the case, then the ability to produce creative shifts could be considered to be one aspect of translational competence and so fostering this ability should take place in the translator classroom. As TransComp is rooted in the expertise paradigm, i.e., compares the performance of novices and professionals, it was deemed to be revealing to contrast the performance of students (= "laypersons") with that of professionals (= "experts").

At the heart of the assessment procedure lies a typology of creative shifts. Whereas most existing categorisations of shifts had largely remained on a formoriented, linguistic level, the first approaches to defining cognitive shifts were largely focused on the notions of abstraction and concretisation (see Section 1). My intention was to unite the existing approaches, put them into perspective by integrating evidence from psychological research and establish a clear and exhaustive typology for cognitive shifts comprising abstraction, concretisation and modification (BayerHohenwarter 2009; 2010). The initial assumption was that translators, in their search 
for a skopos-adequate translation, may, and sometimes even must, depart from cognitively less effortful literal translations that only involve re-coding the ST structure word-by-word and resort to more effortful strategies that involve conceptualising the ST meaning beyond what is visible through the ST wording. ${ }^{2}$ Such effortful and hence "creative" strategies result in more abstract, more concrete target texts or target texts that are "different" in some way. Ideally, the communicative function is preserved (see Bayer-Hohenwarter 2009; 2010).

The research described in the following section provides a detailed analysis of one aspect of translational creativity that is not covered by the assessment procedure (Bayer-Hohenwarter 2010) developed for my $\mathrm{PhD}$ research within TransComp in this way. In my creativity assessment procedure, occurrences of the various creative shifts in target texts and interim versions are considered one indicator among others for translational flexibility (which in turn is one aspect of translational creativity). Translational flexibility is, in line with Guilford (1950), conceived as the ability to depart from conventional modes of thinking and thus includes the ability to depart from the linguistic structure of the source text. In the present article, creative shifts, as a manifestation of translational flexibility and hence creativity, are analysed in their own right. This is, incidentally, similar to the analysis undertaken by Bastin and Betancourt (2005).

\section{Design}

Most practising translators, translation teachers and researchers will agree that the ability to produce shifts, i.e., target texts that depart from the linguistic structure of the source text, can be regarded as one important manifestation of translational creativity. Reproduction, i.e., the more or less literal rendering of ST elements, however, would be the opposite, namely non-creative work. For this reason, the typology of creative shifts is now used to measure one aspect of translational creativity in terms of the ability to produce non-reproductive target texts.

\subsection{Scope of analysis}

The corpus of the present analysis was produced by eleven students and ten professional translators who, overall, translated four experimental texts (popular-science texts) of about 200 words (see the documentation provided in Göpferich, BayerHohenwarter et al. 2011). The ten professional translators, however, only translated two experimental texts each. This meant that each experimental text was translated only by five professionals, although by different ones (see Table 1 below). From all four experimental texts, a sample of four units of analysis each (counting between 2 and 36 words) was analysed. All sixteen units of analysis were thus translated 16 times (by eleven students and five professionals), which amounts to a corpus of 256 target text units. Given this large corpus, only the creative shifts evident from target texts can be taken into consideration for the present analysis. If one took into account all creative shifts present in the interim versions, the corpus would presumably increase by an estimated $300 \%$ according to a cautious estimate that, on average, each target text solution is preceded by three interim versions. It is assumed, though, that an extension of the scope of analysis to interim versions will also 
provide noteworthy results; this analysis of process data remains a challenge to be met in future analyses.

The following scheme provides an overview of the number and distribution of translators for each of the four experimental texts. 1_ stands for a $1^{\text {st }}$-semester student, 2 _ for a $2^{\text {nd }}$-semester student, 3 for a $3^{\text {rd }}$-semester student and $P_{-}$for a professional translator; the three-letter abbreviations stand for the participants:

TABLE 1

Distribution scheme of participant translators for the sample analysis

\begin{tabular}{|c|l|l|c|}
\hline Text A1 & Text B1 & Text A2 & Text B2 \\
\hline 1_BKR & 1_EVE & 1_BKR & 1_EVE \\
\hline 1_CHA & 1_JTH & 1_CHA & 1_JZE \\
\hline 1_HHE & 1_JZE & 1_HHE & 1_JTH \\
\hline 1_KNI & 1_STO & 1_KNI & 1_STO \\
\hline 1_SFR & 1_THI & 1_SFR & 1_THI \\
\hline 1_TDI & 2_BKR & 1_TDI & 3_BKR \\
\hline 2_EVE & 2_CHA & 3_EVE & 3_HHE \\
\hline 2_JTH & 2_HHE & 3_JTH & 3_KNI \\
\hline 2_JZE & 2_KNI & 3_JZE & 3_SFR \\
\hline 2_STO & 2_SFR & 3_STO & 3_TDI \\
\hline 2_THI & 2_TDI & 3_THI & P_CAS \\
\hline P_AEF & P_CAS & P_AEF & P_FLS \\
\hline P_AIR & P_FLS & P_AIR & P_GEM \\
\hline P_KEG & P_GEM & P_KEG & P_GOB \\
\hline P_LEB & P_GOB & P_LEB & P_RCH \\
\hline P_RAN & P_RCH & P_RAN & PHA \\
\hline
\end{tabular}

This distribution scheme shows that the same 11 students were participants in the experiments conducted with all four texts but that they were translated at three different measurement points $\left(1^{\text {st }}\right.$ semester, $2^{\text {nd }}$ semester and $3^{\text {rd }}$ semester $)$ at the time when the experiments took place. Which participants translated which texts at what time is in line with the general TransComp translation scheme (see Table 2), but the sample of translators and experimental texts used for the present analysis does not comprise the full number of participants and texts scheduled for the TransComp project.

According to the TransComp translation scheme, all student participants were split in two groups whereby each one of the two groups is asked to translate their four experimental texts at different points of time. More precisely, Group A (comprised of students named BKR, CHA, HHE, KNI, SFR, TDI) started with the texts of the A series in their first semester and progressed towards the B-texts, whereas Group B (EVE, JTH, JZE, STO and THI) started with the B-texts and progressed towards the A-texts. The 10 professional participants were also split into two groups of five so that every professional only had to translate half of the experimental texts (A1 and $\mathrm{A} 2$ or $\mathrm{B} 1$ and $\mathrm{B} 2$ ). 
TABLE 2

Translation scheme

\begin{tabular}{|l|c|c|}
\hline & Group A & Group B \\
\hline Beginning of $1^{\text {st }}$ semester & $\mathrm{A} 1, \mathrm{~A} 2$ & $\mathrm{~B} 1, \mathrm{~B} 2$ \\
\hline Beginning of $2^{\text {nd }}$ semester & $\mathrm{B} 1$ & $\mathrm{~A} 1$ \\
\hline Beginning of $3^{\text {rd }}$ semester & $\mathrm{B} 2$ & $\mathrm{~A} 2$ \\
\hline Professionals & $\mathrm{A} 1, \mathrm{~A} 2$ & $\mathrm{~B} 1, \mathrm{~B} 2$ \\
\hline
\end{tabular}

This explains why the sample of the present analysis comprises $2^{\text {nd }}$-semester students for A1 and B1 and $3^{\text {rd }}$-semester students for A2 and B2. As one student dropped out in her third semester, the existing data produced by this student in her first and second semester were ignored in order to reduce the number of student participants consistently from 12 to 11 and provide for a homogeneous corpus. The drop-out explains why there were unequal numbers of participants for the novice level ( $1^{\text {st }}-$ semester $)$ and for the more advanced level $\left(2^{\text {nd }}\right.$ or $3^{\text {rd }}$ semester $)$. A reduction in the number of $1^{\text {st }}$-semester students to provide an equal number of 5 students for the novice level and for the more advanced level was rejected because this would have involved the risk of bias through my decision on which student data to eliminate.

As for the characteristics of the $1^{\text {st }}-, 2^{\text {nd }}$ - and $3^{\text {rd }}$-semester students, all have enrolled for the BA in transcultural communication at the Institut für Theoretische und Angewandte Translationswissenschaft, the Department of Theoretical and Applied Translation Studies at the University of Graz, with German as their mother tongue and English as their first foreign language. At the beginning of their first semester, they clearly are novices. At the beginning of their second semester, the students have attended a lecture on translation-relevant linguistics and courses on the language and the culture of their first language. At the beginning of their third semester, the students have attended more courses on the language and culture of their first and also of their second language and have usually passed their first important exam that marks the end of the first of two phases of their studies (see the curriculum ${ }^{3}$ for more details).

As for the participants of the present study, there is one exception to these rules. Participant KNI had started her studies with Arabic as her first foreign language and switched over to English after two semesters. For this reason, she is at the beginning of her first semester only with regard to her English courses, whereas she had already attended the lecture on translation-relevant linguistics two semesters before. None of the students, however, has had prior experience with English translations by the time they are in their $3^{\text {rd }}$ semester.

\subsection{Texts, units of analysis and specifications for creative shifts}

The four texts from the TransComp corpus analysed within the scope of the present investigation are all popular-science texts that were selected because they were easy to understand but less easy to translate, i.e., they required a considerable amount of problem awareness and target-text production competence. They were all about 200 words long, had to be translated from English into German and have been published on the TransComp website (Göpferich, Bayer-Hohenwarter et al. 2011).

For each experimental text, a number of units of analysis were defined. The selection criterion for those units of analysis was that they should be potentially 
promising and highly relevant for the research questions to be answered. In the case of a study on the development of translational creativity, such promising units of analysis bore either a high creativity potential or a low creativity potential (= a high routine potential). Units with a high creativity potential (short: "creativity units") are defined as problematic units that are deemed to require high problem-solving capacity. Units with a high routine potential (short: "routine units") were such that they were regarded as fairly unproblematic, at least for experienced translators. For each experimental text, 2 creativity units and 2 routine units were selected. Even if it is acknowledged that the attribution of the label "creative" versus "routine" is subjective to a certain extent, this distinction proved generally consensual and useful in a pilot study (see Bayer-Hohenwarter 2010 for more details).

As for the specification of abstractions, modifications and concretisations as opposed to mere reproductions, the rules laid down in my previous publications (Bayer-Hohenwarter 2009; 2010) were followed. The most important rule is that reproductions are "literal" translations of a chunk of text that can legitimately be expected to require the translator to invest less cognitive effort than for a creative shift (see Bayer-Hohenwarter 2009 for the rationale behind this assumption). Though it is acknowledged that no single way of defining abstraction, modification or concretisation for a particular chunk of text exists, any specification is considered to be acceptable as long as the reproduction can reasonably be regarded as more literal and potentially more effortless, as in the example below. Whereas the classification established by Bastin and Betancourt (2005) was based on different degrees of non-literalness, no distinction in the degree of non-literalness was made among my creative shifts. The following example serves to illustrate how my typology was applied whereby the unit of analysis, which is classified as a creativity unit, is the underlined part of the ST:

(1) ST: Or to take further examples: what of the men who work their heads off trying to acquire their tenth million dollars; or the office girls who go without lunch in order to make payments on fur coats that they cannot afford; or the people who risk their lives in the five-hundred-mile races on Memorial Day at Indianapolis, or in expeditions to scale Mount Everest, or in attempts to go over Niagara Falls in a barrel?

TT1: [...] oder die Leute, die an dem fünfhundert-Meilen-Rennen am Memorial Day in Indianapolis teilnehmen, auf Expeditionen den Mount Everest besteigen oder versuchen in einem Fass die Niagarafälle hinabzustürzen und dabei ihr Leben riskieren (t2_Stud_HHE)

TT2: [...] oder mit den Menschen, die ihr Leben riskieren beim Versuch, den Mount Everest zu erklimmen oder die Niagarafälle in einem Fass zu durchqueren (t2_Stud_BKR)

TT3: Und was ist mit den Menschen, die ihr Leben riskieren um den Mount Everest zu besteigen, oder um sich in einem Fass die Niagarafälle hinunterzustürzen, oder um am Memorial Day in Indianapolis beim 500-Meilen-Rennen teilzunehmen (t2_Stud_KNI)

TT4: [...] oder mit dem Sportler, der sein Leben beim Autorennen von Indianapolis auf's Spiel setzt, auf einer Expedition auf den Mount Everest oder beim Versuch, die Niagarafälle in einem Fass hinunter zu stürzen (t8_Prof_FLS)

TT5: Oder was ist mit den Menschen, die ihr Leben bei der Wüstenrallye ParisDakar, bei Expeditionen auf den Mount Everest oder beim Basejumping vom Empire State Building aufs Spiel setzen (GBH/FPR) 
TT6: Oder was ist mit den Menschen, die ihr Leben bei mörderischen Sportevents, aben-teuerlichen Expeditionen oder halsbrecherischen Mutproben riskieren $(\mathrm{GBH})$

The ST chunk in this example is from a popular-science text entitled The SelfConcept in which the author ${ }^{4}$ argues that people in our modern times do not primarily strive at self-preservation, but in the preservation of their self-concept, i.e., their view of their own role with its underlying system of values. The ST chunk gives a number of examples used by the author to illustrate what unreasonable and even life-threatening actions people undertake in order to preserve their self-concept.

If, as in TT1, a translator translates the ST by using the same three examples in the same sequence and in a wording similar to the ST, this is considered a "reproduction." TT2, TT3 and TT4 represent "modifications" because the culture-specific example "in the five-hundred-mile races on Memorial Day at Indianapolis" is omitted (TT2), put to the end of the list of three (TT3) or modified (TT4: "beim Autorennen von Indianapolis") in order to make the text more comprehensible for a non-American audience that is not necessarily interested in car races. TT5 is an example of a "concretisation" because at least one ST example is replaced by a TT example that is more prototypical and hence concrete for the TT culture. TT6 exemplifies an "abstraction" because the ST examples are replaced by more generic ones.

As can be seen from these examples, the creative shifts are cognitive categories as opposed to traditional shift concepts like "addition," "change" or "omission" that are form-oriented categories only. Even if in TT2 an example is deleted, i.e., "omission," this does not lead to an abstraction and even if in TT5 and TT6 ST elements are replaced by different TT elements, i.e., "change," they are assigned different cognitive shifts ("concretisation" and "abstraction" respectively).

Another important characteristic of the creative shifts is that they are not good or bad in themselves with respect to translation quality; the target texts presented in the example above are by no means faultless. With some units of analysis, as in the present one, reproductions lead to inadequate target texts only; with some units of analysis, only reproductions led to adequate target texts and with others, both reproductions and (certain) creative shifts can lead to adequate target texts. For a final assessment of creativity, the quality of the target text must be taken into consideration - be it in the form of general skopos adequacy, linguistic faultlessness or relative acceptability measured in terms of a low number of errors. Regardless of this quality judgment, the presence of a creative shift is regarded as an indicator of translational flexibility. This flexibility is regarded as a form of problem-solving ability that can be used by translators whenever a literal translation proves unsatisfactory. Presumably, particularly in the case of more experienced translators, their understanding of the source text directly triggers a non-structure-oriented primary association that leads to creative shifts, perhaps via certain imaginative reflexes (see Kußmaul's notion of "visualization" in translation).

Thus, contrary to the approach taken by Bastin and Betancourt (2005), erroneous target texts were not excluded from my analysis for two reasons. Firstly, the existence of creative shifts was nonetheless considered as an expression of creativity. Secondly, the approach of Bastin and Betancourt (2005) is deemed to yield falsified results because the authors did not count translation units containing a semantic error but nevertheless compared two translations of the same ST produced by the same trans- 
lators at different points of time. This means that, if e.g., the first version was not counted because of a semantic error but the second was, the authors did not compare the same number of translation units. In other words, Bastin's and Betancourt's criteria "novelty" (= creative shifts) and "acceptability" were not separated but blended and so the results cannot be assessed quantitatively in terms of novelty alone. To avoid this methodological problem, the analysis of acceptability was undertaken only after the count of shifts in my study.

More details of the nature of creative shifts and examples of shifts applied in the present analysis can be found in Bayer-Hohenwarter (2009; 2010).

\subsection{Calculation procedure}

For each unit of analysis, the criteria for the various types of shifts and for reproduction were defined. ${ }^{5}$ Each target text of every single unit of analysis was analyzed according to these pre-defined criteria in order to determine if a creative shift or a reproduction had been produced. For each participant translator and for each of the four units of analysis belonging to the same experimental text, the sum of reproductions, abstractions, modifications and concretisations was established. All points for creative shifts were again summed up and contrasted with the value obtained for the reproductions. The results were transformed into percentages indicating how many of the four units of analysis were creative as opposed to reproductive:

TABLE 3

Sample calculation: Individual averages for one experimental text

\begin{tabular}{|c|c|c|c|}
\hline Unit A1_1K & 1_BKR & 1_CHA & 1_HHE \\
\hline Reproduction & 1 & 1 & 0 \\
\hline Abstraction & 0 & 0 & 0 \\
\hline Modification & 0 & 0 & 1 \\
\hline Concretisation & 0 & 0 & 0 \\
\hline Creative shifts & 0 & 0 & 1 \\
\hline Unit A1_2R & 1_BKR & 1_CHA & 1_HHE \\
\hline Reproduction & 1 & 0 & 0 \\
\hline Abstraction & 0 & 0 & 1 \\
\hline Modification & 0 & 1 & 0 \\
\hline Concretisation & 0 & 0 & 0 \\
\hline Creative shifts & 0 & 1 & 1 \\
\hline Unit A1_3K & 1_BKR & 1_CHA & 1_HHE \\
\hline Reproduction & 1 & 1 & 1 \\
\hline Abstraction & 0 & 0 & 0 \\
\hline Modification & 0 & 0 & 0 \\
\hline Concretisation & 0 & 0 & 0 \\
\hline Creative shifts & 0 & 0 & 0 \\
\hline Unit A1_4R & 1_BKR & 1_CHA & 1_HHE \\
\hline Reproduction & 1 & 1 & 0 \\
\hline Abstraction & 0 & 0 & 0 \\
\hline Modification & 0 & 0 & 1 \\
\hline Concretisation & 0 & 0 & 0 \\
\hline Creative shifts & 0 & 0 & 1 \\
\hline Text A1, total & 1_BKR & 1_CHA & 1_HHE \\
\hline Reproduction & $100 \%$ & $75 \%$ & $25 \%$ \\
\hline Abstraction & $0 \%$ & $0 \%$ & $25 \%$ \\
\hline Modification & $0 \%$ & $25 \%$ & $50 \%$ \\
\hline Concretisation & $0 \%$ & $0 \%$ & $0 \%$ \\
\hline Creative shifts & $0 \%$ & $25 \%$ & $75 \%$ \\
\hline
\end{tabular}


In this sample, the student BKR produced only reproductions, the student $\mathrm{CHA}$ produced one creative shift (a modification), and the student HHE produced two modifications and one abstraction. Their scores for creative shifts, as measured through the proportion of creative shifts, were $0 \%, 25 \%$ and $75 \%$ respectively.

To improve the comprehensibility of the calculation procedure, a schematic diagram is given in Figure 1:

FIGURE 1

Calculation of individual scores per experimental text

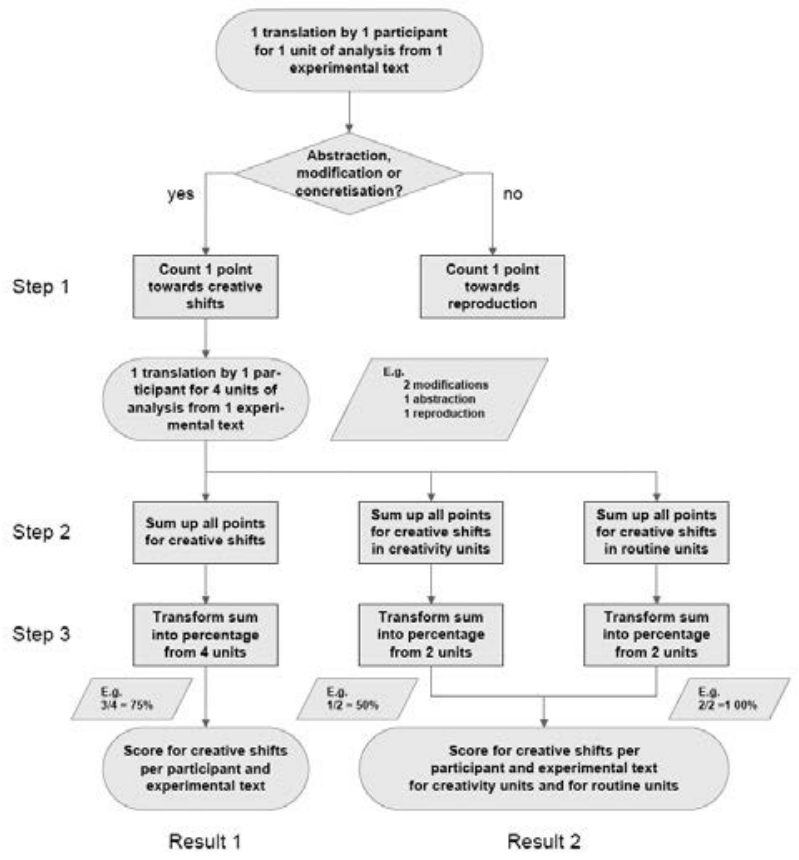

In this diagram, ovals stand for states, rectangles for actions, banners for results and rhombs for examples.

As a next step, these basic results were used to investigate the creative performance of individual translators and the group performance of participants with the same formal level of competence.

\subsubsection{Calculation of individual performance}

For the analysis of the performance of individual translators across all experimental texts, the total percentages indicating the proportion of creative shifts for each experimental text, as seen from the last row in Table 3 above, were listed for each participant and for each text translated. For the professionals, this led to two entries in the list because they translated either two texts from the A-series or from the $\mathrm{B}$-series depending on what group they belonged to (see 3.1). For the student translators, this led to four entries in the list because they translated all four texts, but at different stages in their translator training. According to Table 4 below, the professional (P) AIR translated two A-texts (A1, A2). The student BKR translated two A-texts and two B-texts in her first, second and third semester. 
TABLE 4

Sample calculation: Individual averages across all texts translated

\begin{tabular}{|c|c|c|c|c|c|c|}
\hline Participants & $\begin{array}{c}\text { Proportion } \\
\text { of creative } \\
\text { shifts }\end{array}$ & $\begin{array}{c}\text { Proportion of } \\
\text { creative shifts } \\
\text { for creativity } \\
\text { units }\end{array}$ & \begin{tabular}{|c} 
Proportion of \\
creative shifts \\
for routine \\
units
\end{tabular} & $\begin{array}{c}\text { Average (Ø) } \\
\text { proportion of } \\
\text { creative shifts }\end{array}$ & $\begin{array}{l}\emptyset \text { proportion } \\
\text { of creative } \\
\text { shifts for } \\
\text { creativity units }\end{array}$ & $\begin{array}{l}\text { Ø proportion } \\
\text { of creative } \\
\text { shifts for } \\
\text { routine units }\end{array}$ \\
\hline AIR_A1_P & $50 \%$ & $0 \%$ & $100 \%$ & \multirow{2}{*}{$63 \%$} & \multirow{2}{*}{$50 \%$} & \multirow{2}{*}{$75 \%$} \\
\hline AIR_A2_P & $75 \%$ & $100 \%$ & $50 \%$ & & & \\
\hline BKR_A1_1 & $0 \%$ & $0 \%$ & $0 \%$ & \multirow{4}{*}{$31 \%$} & \multirow{4}{*}{$50 \%$} & \multirow{4}{*}{$13 \%$} \\
\hline BKR_A2_1 & $50 \%$ & $100 \%$ & $0 \%$ & & & \\
\hline BKR_B1_2 & $50 \%$ & $100 \%$ & $0 \%$ & & & \\
\hline BKR_B2_3 & $25 \%$ & $0 \%$ & $50 \%$ & & & \\
\hline
\end{tabular}

In order to find out about the performance of individual translators across different experimental texts and, as in the case of students, regardless of their formal level of competence, an average was established for the performance with individual texts. This was done by summing up the values from the table column Proportion of creative shifts and dividing the sum by the number of texts translated. In the examples of Table 4, this shows that the student BKR is less creative than the professional AIR.

Additionally, the results for the individual units of analysis presented in Table 3 were summed up for the 2 creative units only and for the 2 routine units only. The results are listed in the table columns Proportion of creative shifts for creative units and Proportion of creative shifts for routine units in Table 4. In order to find out if there is a difference in performance depending on the type of unit (creativity or routine), an average was formed for these partial results. In the example above, the professional AIR turns out to be much more creative with the 2 routine units of $\mathrm{A} 1$ and the two routine units of $\mathrm{A} 2$ than the student BKR in the 4 routine units that she translated (75\% vs. 13\%). With the creativity units, however, their performance is equal (50\%). It is acknowledged that the basis for comparison is unequal because the student averages are based on the results for four texts whereas the results for the professionals are based on only two texts. Nevertheless, a comparison of averages is admissible.

As before, the calculation procedure is visualised in Figure 2:

\subsubsection{Calculation of group performance}

In order to find out whether the students or the professionals were more creative and what type of development trend could be observed, the results for the 16 participants were transformed into average values per group of participants according to their formal level of competence (i.e., first semester, second semester, professional etc.). Moreover, the group averages were calculated for the two creativity units and the routine units separately.

\section{TABLE 5}

Sample calculation: Group averages for creative shifts in experimental text B1

\begin{tabular}{|l|c|c|c|}
\hline B1 total & $\varnothing \mathbf{B 1}$ total & $\emptyset$ creativity units & $\emptyset$ routine units \\
\hline $1^{\text {st }}$-semester students $(\mathrm{t} 1)$ & $30 \%$ & $30 \%$ & $30 \%$ \\
\hline $2^{\text {nd }}$-semester students $(\mathrm{t} 2)$ & $33 \%$ & $33 \%$ & $33 \%$ \\
\hline Professionals $(\mathrm{t} 8)$ & $65 \%$ & $80 \%$ & $50 \%$ \\
\hline Average $\varnothing$ & $42 \%$ & $47 \%$ & $38 \%$ \\
\hline
\end{tabular}


In a next step, the averages per competence level and category were summed up and total averages across all four experimental texts and for all three groups $\left(1^{\text {st }}\right.$ semester students, $2^{\text {nd }}$-semester students, and professionals) were established for the sum of 16 units of analysis and for the 8 creativity and 8 routine units separately. The calculation procedure is presented in Figure 3:

FIGURE 2

Calculation of individual averages for total of experimental texts

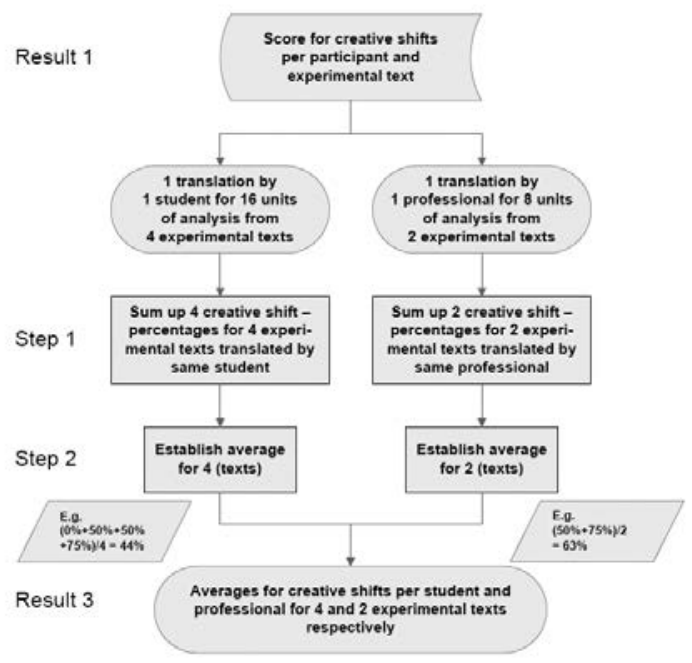

FIGURE 3

Calculation of group averages for total of experimental texts

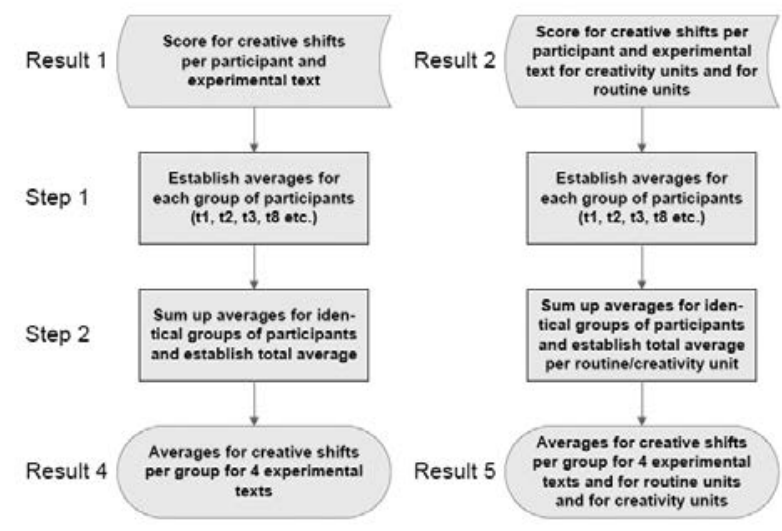


Next, the creativity of the participants is assessed against the background of acceptability.

\subsubsection{Calculation of acceptability}

The results from the quality assessment of the participants' target texts in terms of deductions for errors according to Göpferich (2010a; 2010b) were summed up for all units of analysis of one experimental text. Next, the maximum value of errors produced by any one of the 16 translators was identified and transformed into $100 \%$. Lower error numbers were transformed into lower percentages accordingly, participants with 0 error points (indicating an error-free version) were assigned $0 \%$.

This procedure was applied for two reasons. First, the absolute values are textspecific and the number of participants is different for the various texts and so the calculation of averages across several experimental texts requires that absolute values be transformed into percentages. Secondly, transformation into percentages requires a division and hence a divisor, but there is no "natural" (a priori) maximum for each unit of analysis, i.e., no maximum value of errors is inherent in the unit of analysis. For this reason, the divisor must be determined by identifying the empirical maximum number of errors, which, as it is a negative value, is a mathematical minimum. This transformation procedure is illustrated in the following example:

TABLE 6

Sample calculation: Percentages according to mathematical standardisation procedure

\begin{tabular}{|l|c|c|c|c|c|}
\hline \multicolumn{1}{|c|}{ A1 } & Error points & $\begin{array}{c}\text { Error rate, } \\
\text { relative }\end{array}$ & A2 & Error points & $\begin{array}{c}\text { Error rate, } \\
\text { relative }\end{array}$ \\
\hline P_GEM & $-1,5$ & $100 \%$ & P_GEM & $-1,5$ & $43 \%$ \\
\hline P_GOB & 0 & $0 \%$ & P_GOB & $-0,5$ & $14 \%$ \\
\hline P_RCH & 0 & $0 \%$ & P_RCH & $-3,5$ & $100 \%$ \\
\hline Minimum: & $-1,5$ & & Minimum: & $-3,5$ & \\
\hline
\end{tabular}

Through this mathematical standardization procedure, a range of percentages is defined that can be compared with ranges based on a different distribution of absolute values. In the example above, the performance of the professional translators GEM, GOB and RCH as measured for the translation of A1 and A2 respectively can be compared. Throughout this procedure, the relations between the original values and the relative values remain identical.

After the standardization procedure had been applied to the results of one experimental text, the error ratios were inverted to establish acceptability ratios. An error ratio of $100 \%$ thus became an acceptability ratio of $0 \%$, an error ratio of $25 \%$ became an acceptability ratio of $75 \%$, and so on. The acceptability ratios were then summed up for all 4 experimental texts and averages were established for the groups of participants belonging to one competence level.

The calculation procedure is presented in Figure 4: 
FIGURE 4

Calculation of (average) acceptability ratios

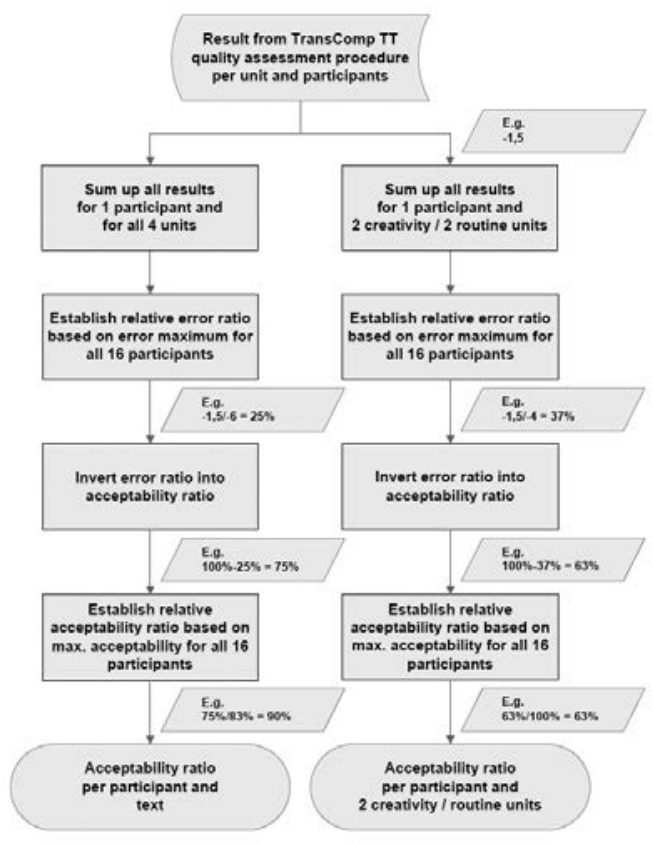

The results of my calculations according to the procedures outlined in this section are presented in the following.

\section{Results ${ }^{6}$}

The calculations outlined in the previous section were carried out with the aim to find out if fostering creative thinking in the form of abstracting, concretising and changing the perspective when producing target texts, is conducive to increasing translation competence (see section 1.5). Although the performance of professionals will most probably prove to be of higher overall quality, it cannot be taken for granted that the quality of their work will outperform that of the students in every case and in all respects. Also, the production of creative shifts is not desirable for all translation units. For this reason, three assumptions, which are all derived from the main assumption, are put to the test in the present study:

A1: Translators who produce more creative shifts achieve higher quality results.

A2: Professionals produce more creative shifts.

A3: Professionals produce more creative shifts with creativity units.

It may appear as a contradiction, though, that creativity and quality (=acceptability) are treated as two distinct categories in these assumptions, whereas it was stated at the beginning that "true creativity" requires acceptability. For methodological reasons, however (for example as outlined in section 2.2 in connection with the study by Bastin and Betancourt 2005) it is necessary to measure certain expressions of creativity such as flexibility, novelty, or creativity occurrring in the translation 
process, without taking acceptability into account and to measure acceptability separately. This is also necessary because abilities such as "departing from conventional thinking" do not always lead to measurable results or cannot be linked directly and unequivocally to a particular measurable result. Also, unconventional cognitive strategies can lead to an acceptable result in one case and to an unacceptable result in another. Therefore, as in the present study, it appears to be indispensable to measure a pre-stage of creativity, i.e., a form of potential creativity or "pre-creativity." At the same time it is fully acknowledged that "true creativity" is a slightly different concept at an even higher rank. "True creativity" is the ultimate goal in terms of a creative performance leading to a clearly measurable acceptable outcome.

According to the calculation procedures explained in section 2, the results of three types of analysis are now reported. Here, these three types of analysis do not directly relate to one of the above assumptions. The first analysis provides information about the degrees of creative performance achieved by participants with different levels of competence with a view to establishing group averages. The second analysis investigates inter-individual differences that go unnoticed in the group averages. The third analysis investigates the relationship between creative shifts and acceptability with the intention of finding an explanation for any incongruent results.

\subsection{Creativity vs. reproduction in students and professionals}

The calculation of group performance according to section 2.3.2 provides the following results:

TABLE 7

Group averages for creative shifts for all four experimental texts

\begin{tabular}{|c|c|c|c|}
\hline A1 total & $\varnothing$ A1 total & $\emptyset$ creativity units & $\emptyset$ routine units \\
\hline $1^{\text {st }}$-semester students (t1) & $46 \%$ & $33 \%$ & $58 \%$ \\
\hline $2^{\text {nd }}-$ semester students (t2) & $50 \%$ & $40 \%$ & $60 \%$ \\
\hline$\varnothing$ professionals (t8) & $60 \%$ & $40 \%$ & $80 \%$ \\
\hline Total & $52 \%$ & $38 \%$ & $66 \%$ \\
\hline B1 total & $\varnothing$ B1 total & $\varnothing$ creativity units & $\varnothing$ routine units \\
\hline $1^{\text {st }}$-semester students (t 1$)$ & $30 \%$ & $30 \%$ & $30 \%$ \\
\hline $2^{\text {nd }}-$ semester students ( $\mathrm{t} 2$ ) & $33 \%$ & $33 \%$ & $33 \%$ \\
\hline$\varnothing$ professionals (t8) & $65 \%$ & $80 \%$ & $50 \%$ \\
\hline Total & $42 \%$ & $47 \%$ & $38 \%$ \\
\hline A2 total & $\varnothing$ A2 total & $\varnothing$ creativity units & $\varnothing$ routine units \\
\hline $1^{\text {st }}$-semester students (t1) & $42 \%$ & $67 \%$ & $17 \%$ \\
\hline $3^{\text {rd }}$-semester students $(\mathrm{t} 3)$ & $85 \%$ & $100 \%$ & $70 \%$ \\
\hline$\varnothing$ professionals (t8) & $90 \%$ & $100 \%$ & $80 \%$ \\
\hline Total & $70 \%$ & $88 \%$ & $53 \%$ \\
\hline B2 total & $\varnothing \mathrm{B} 2$ total & $\varnothing$ creativity units & $\varnothing$ routine units \\
\hline $1^{\text {st }}$-semester students (t1) & $40 \%$ & $50 \%$ & $30 \%$ \\
\hline $3^{\text {rd }}$-semester students $(\mathrm{t} 3)$ & $63 \%$ & $75 \%$ & $50 \%$ \\
\hline$\varnothing$ professionals (t8) & $70 \%$ & $100 \%$ & $40 \%$ \\
\hline Total & $58 \%$ & $75 \%$ & $41 \%$ \\
\hline Total & $\varnothing$ total & $\varnothing$ creativity units & $\varnothing$ routine units \\
\hline
\end{tabular}




\begin{tabular}{|l|l|l|l|}
\hline $1^{\text {st }}$-semester students (t1) & $39 \%$ & $45 \%$ & $34 \%$ \\
\hline $2^{\text {nd }}$-semester students (t2) & $42 \%$ & $37 \%$ & $47 \%$ \\
\hline $3^{\text {rd }}$-semester students (t3) & $74 \%$ & $88 \%$ & $60 \%$ \\
\hline$\varnothing$ professionals & $71 \%$ & $80 \%$ & $63 \%$ \\
\hline$\varnothing$ total & $56 \%$ & $62 \%$ & $50 \%$ \\
\hline$\varnothing$ students & $49 \%$ & $54 \%$ & $44 \%$ \\
\hline
\end{tabular}

In total, the average of the professionals (71\%) is almost double that of the $1^{\text {st }}$ semester students' average (39\%) and a continuously rising trend is observed from the first to the second and from the second to the third semester. Surprisingly, the average of the $3^{\text {rd }}$-semester students (74\%) is slightly higher (by 3\%) than that of the professionals (71\%). For the creativity units, the same trends are observed, with the exception that the average of the $1^{\text {st }}$-semester students is higher than that of the $2^{\text {nd }}$ semester students and that the ratio of creative shifts produced by the $3^{\text {rd }}$-semester students exceeds that of the professionals to a higher degree (by 8\%). With the routine units, the professionals "outperform" the students and the trend continuously rises from the $1^{\text {st }}$-semester students to the professionals. The $2^{\text {nd }}$-semester students (as compared with the $1^{\text {st }}$-semester students) make progress in the translation of the routine units but not of the creativity units; the progress of the $3^{\text {rd }}$-semester students is greater with the creativity units.

By way of conclusion, this only partially supports the assumption that the professionals would outperform the students (A2). The performance of the students in general and of the $1^{\text {st }}$ - and $2^{\text {nd }}$-semester students was certainly lower, but the performance of the $3^{\text {rd }}$-semester students and the professionals was nearly equal. The assumption that professionals would produce more creative shifts with creativity units (A3) was contradicted. For the routine units, the professionals surprisingly produced more creative shifts compared to the students.

One could argue that these results indicate that the ability to create creative shifts must be learned. However, the students, who were following the BA programme of studies taught at the department of translation at the University of Graz, did not receive any such explicit training in their first two semesters. Actually, translation (methodology) seminars do not start before the fifth semester, whereas the first two years are reserved for language seminars, culture seminars and translation theory. For this reason, it seems more plausible that the novices wrongly think that literalness is a generally valid quality criterion in the production of target texts. With the $2^{\text {nd }}$ semester students, only a slight overall increase in creativity is noticeable, whereby the most pronounced increase occurs with the routine units. This increase in creative shifts with the routine units produced by the $2^{\text {nd }}$-semester students can possibly be attributed to their linguistic training that has increased their vocabulary and ST comprehension competence. With the creativity units, the decrease in the use of creative shifts by the $2^{\text {nd }}$-semester students can be interpreted as a period of "incubation" in the widest sense, i.e., a time when new impulses from the training received during the first semester are slowly and tacitly being integrated into existing mental structures. At the same time, knowledge and attitudes are re-organised and problem awareness is increased. The $3^{\text {rd }}$-semester students, who have received training in translation theory and passed their language and culture exams, seem to have developed awareness for more reasonable quality criteria and may have developed a more self-confident attitude towards deviations from literalness. 
Similar to my own results, Bastin and Betancourt (2005: 220) also did not observe a significant decrease in literalness over the first semester (6\%). The increase in translation quality, however, was considerable and seems to be attributable to the 15-week training the students received in translation methodology. The extremely high increase in shifts (paraphrases and new translations) in their study could, to a large extent, have been caused by the participants' quality improvement. As Bastin and Betancourt excluded inadequate translations, this can be assumed to have ruled out many shifts in novice translations. This is compatible with my finding that creative shifts are more often observed in conjunction with inadequate translations by the less proficient students but less so by professionals (see section 4.3. for details). It must also be emphasised at this point that the results of the study carried out by Bastin and Betancourt cannot be directly compared with mine because the strictness with which Bastin and Betancourt operationalised "literalness" cannot be checked for lack of examples.

The following results now go beyond the categories analysed by Bastin and Betancourt.

\subsection{Inter-individual differences in the use of creative shifts}

The calculation of individual averages according to 2.3.1 provided the following results:

TABLE 8

Individual averages for creative shifts for all experimental texts translated

\begin{tabular}{|l|c|c|c|}
\hline Students & $\varnothing$ total & $\emptyset$ creativity units & Ø routine units \\
\hline BKR & $31 \%$ & $38 \%$ & $25 \%$ \\
\hline CHA & $22 \%$ & $6 \%$ & $38 \%$ \\
\hline EVE & $44 \%$ & $50 \%$ & $38 \%$ \\
\hline HHE & $56 \%$ & $44 \%$ & $69 \%$ \\
\hline JTH & $41 \%$ & $44 \%$ & $38 \%$ \\
\hline JZE & $53 \%$ & $50 \%$ & $56 \%$ \\
\hline KNI & $59 \%$ & $69 \%$ & $50 \%$ \\
\hline SFR & $38 \%$ & $44 \%$ & $31 \%$ \\
\hline STO & $66 \%$ & $63 \%$ & $69 \%$ \\
\hline TDI & $44 \%$ & $25 \%$ & $63 \%$ \\
\hline THI & $53 \%$ & $31 \%$ & $75 \%$ \\
\hline Professionals & $\varnothing$ total & $\varnothing$ creativity units & $\varnothing$ routine units \\
\hline AEF & $63 \%$ & $75 \%$ & $50 \%$ \\
\hline AIR & $63 \%$ & $50 \%$ & $75 \%$ \\
\hline CAS & $50 \%$ & $38 \%$ & $63 \%$ \\
\hline FLS & $50 \%$ & $50 \%$ & $50 \%$ \\
\hline GEM & $50 \%$ & $50 \%$ & $50 \%$ \\
\hline GOB & $56 \%$ & $63 \%$ & $50 \%$ \\
\hline KEG & $88 \%$ & $100 \%$ & $75 \%$ \\
\hline LEB & $88 \%$ & $75 \%$ & $100 \%$ \\
\hline RAN & $75 \%$ & $50 \%$ & $100 \%$ \\
\hline RCH & $38 \%$ & $50 \%$ & $25 \%$ \\
\hline
\end{tabular}

The best results are highlighted in grey. 
This table shows that the students with over-average results for all four experimental texts (16 units of analysis) translated were HHE, JZE, KNI, STO and THI. This result comes as a surprise because a pilot study (Bayer-Hohenwarter 2010) had revealed that JZE and STO were, at least for text B2, particularly low-performing students with low overall creativity scores and low translation quality.

With the professionals, the best-performing participants, i.e., those with a $100 \%$ score in at least one category, were KEG, LEB and RAN. All other professionals produced near-average results. In some cases, as with CAS and $\mathrm{RCH}$, the differences between the average for the creativity units and that for the routine units were striking. CAS, for instance, was considerably less creative with the creativity units than with the routine units, and for $\mathrm{RCH}$ the reverse case applies. These findings can perhaps one day be used for "profiling" translators depending on their problemsolving styles. Translators who show particularly high creativity with creativity units might be better able to solve creativity-demanding problems whereas other translators might be better suited for translating texts with high routine potential.

In sum, the results of this analysis reveal a considerable amount of interindividual differences, sometimes also depending on the type of unit of analysis (creativity vs. routine). In order to find out what these inter-individual differences could indicate and how the concomitance of a high proportion of creative shifts and quality failure can be explained, the following analysis was made.

\subsection{Creative shifts and acceptability in students and professionals}

As outlined at the beginning, "true" creativity requires acceptability. In the case of the concepts "creative shifts" and "reproduction," these manifestations of translational flexibility have no inherent quality, i.e., not every creative shift represents a correct translation and some reproductions can be correct translations. For this reason, it was deemed necessary to contrast the results from the previous two sections, i.e., the "pre-creativity" scores, with the quality of the translations concerned. Acceptability is here defined as a relatively error-free target text, whereby only translation-induced errors were counted, but no TL errors like grammatical or orthographic errors.

The comparison of acceptability ratios and creative shift averages for groups of participants according to the procedure specified in 2.3.3 leads to the following result:

TABLE 9

Comparison of group averages for acceptability and creative shifts

\begin{tabular}{|c|c|c|c|c|c|c|}
\hline Total & $\begin{array}{c}\emptyset \text { accepta- } \\
\text { bility, } \\
\text { relative }\end{array}$ & $\begin{array}{c}\emptyset \text { accepta- } \\
\text { bility for } \\
\text { creativity } \\
\text { units, relative }\end{array}$ & $\begin{array}{c}\emptyset \text { accepta- } \\
\text { bility for } \\
\text { routine units, } \\
\text { relative }\end{array}$ & $\begin{array}{c}\emptyset \text { creative } \\
\text { shifts, total }\end{array}$ & $\begin{array}{c}\emptyset \text { creative } \\
\text { shifts for } \\
\text { creative units }\end{array}$ & $\begin{array}{c}\emptyset \text { creative } \\
\text { shifts for } \\
\text { routine units }\end{array}$ \\
\hline $\mathrm{t} 1$ & $33 \%$ & $44 \%$ & $28 \%$ & $39 \%$ & $45 \%$ & $34 \%$ \\
\hline $\mathrm{t} 2$ & $59 \%$ & $57 \%$ & $55 \%$ & $42 \%$ & $37 \%$ & $47 \%$ \\
\hline $\mathrm{t} 3$ & $62 \%$ & $75 \%$ & $57 \%$ & $74 \%$ & $88 \%$ & $60 \%$ \\
\hline $\mathrm{t} 8$ & $75 \%$ & $70 \%$ & $77 \%$ & $71 \%$ & $80 \%$ & $63 \%$ \\
\hline
\end{tabular}

It shows similar trends for acceptability and creative shifts. These results generally seem to support my assumption A1. What these results fail to provide, however, 
is a direct link between acceptability and the occurrence of creative shifts. The similarity of trends could thus be purely accidental.

Therefore, calculating the individual averages for acceptability according to the same procedure outlined for the individual averages of creative shifts in 2.3.1 seems to be the more promising approach:

TABLE 10

Individual averages of acceptability for all experimental texts translated

\begin{tabular}{|l|c|c|c|}
\hline Students & $\varnothing$ total & $\emptyset$ creativity units & $\emptyset$ routine units \\
\hline BKR & $49 \%$ & $66 \%$ & $40 \%$ \\
\hline CHA & $44 \%$ & $52 \%$ & $40 \%$ \\
\hline EVE & $46 \%$ & $57 \%$ & $36 \%$ \\
\hline HHE & $53 \%$ & $67 \%$ & $44 \%$ \\
\hline JTH & $45 \%$ & $63 \%$ & $32 \%$ \\
\hline JZE & $29 \%$ & $28 \%$ & $43 \%$ \\
\hline KNI & $70 \%$ & $78 \%$ & $58 \%$ \\
\hline SFR & $63 \%$ & $64 \%$ & $49 \%$ \\
\hline STO & $29 \%$ & $40 \%$ & $22 \%$ \\
\hline TDI & $59 \%$ & $56 \%$ & $61 \%$ \\
\hline THI & $44 \%$ & $48 \%$ & $50 \%$ \\
\hline Professionals & $\varnothing$ total & $\emptyset$ creativity units & $\emptyset$ routine units \\
\hline AEF & $82 \%$ & $81 \%$ & $55 \%$ \\
\hline AIR & $72 \%$ & $63 \%$ & $65 \%$ \\
\hline CAS & $80 \%$ & $83 \%$ & $85 \%$ \\
\hline FLS & $71 \%$ & $92 \%$ & $69 \%$ \\
\hline GEM & $51 \%$ & $8 \%$ & $94 \%$ \\
\hline GOB & $83 \%$ & $96 \%$ & $73 \%$ \\
\hline KEG & $71 \%$ & $44 \%$ & $100 \%$ \\
\hline LEB & $60 \%$ & $50 \%$ & $70 \%$ \\
\hline RAN & $80 \%$ & $81 \%$ & $58 \%$ \\
\hline RCH & $100 \%$ & $100 \%$ & $100 \%$ \\
\hline
\end{tabular}

The best results are highlighted in grey.

In terms of acceptability, the best-performing students (those with over-average results) were HHE, KNI, SFR and TDI (highlighted in the table). The best-performing professionals (with at least one time $100 \%$ or close to $100 \%$ ) were RCH, KEG and GOB. By contrasting these individual averages with the individual averages for the creative shifts, an overlap, i.e., top results for creative shifts and acceptability, only shows in three cases, for HHE, KNI and KEG. This contradicts assumption A1 (“Translators who produce more creative shifts achieve higher-quality results").

Alternatively, another method of analysis was applied. For every single translation of each of the 16 units of analysis, the results of the shift analysis and of the quality assessment were compared. This time, however, acceptability was defined in terms of an error-free result. Non-acceptability, here, corresponds to all erroneous translations, regardless of the error weight or type (except TL errors, e.g., orthography or grammar).

The results were as follows for the 256 units of analysis under scrutiny: 
TABLE 11

Direct relationship between acceptability and creative shifts

\begin{tabular}{|l|c|c|c|c|c|}
\hline & A1 & B1 & A2 & B2 & Total \\
\hline creative shift \& error-free TT & 9 & 7 & 14 & 29 & 59 \\
\hline reproduction \& erroneous TT & 23 & 35 & 19 & 20 & 97 \\
\hline reproduction \& error-free TT & 10 & 2 & 0 & 7 & 19 \\
\hline creative shift \& erroneous TT & 22 & 20 & 31 & 8 & 81 \\
\hline
\end{tabular}

The conditions in the first two lines, "creative shift \& error-free TT" and "reproduction \& erroneous TT" support assumption A1 (Translators who produce more creative shifts achieve higher-quality results). If one sums up the total number of cases for which these two ideal characteristics prove true, then we have 156 cases (=61\%) that support assumption A1 whereas 100 cases do not. In addition, and also in support of A1, students tended to produce more unsuccessful results when applying a creative shift than professionals did. From the 81 creative shifts that represented an unsuccessful translation, 54 (i.e., 67\%) were produced by the students and only $33 \%$ by the professionals.

This type of analysis thus provides us with a more telling result that does not contradict assumption A1, even if it cannot be established with certainty whether any error has been directly caused by the use of a certain shift or reproduction. Eventually, it must be acknowledged that reliable evidence about the relationship between acceptability and creativity as measured in terms of creative shifts requires even deeper analyses to be made. Such analyses could examine error causes and particularities of the individual units of analysis. For instance, it could be worthwhile to analyse only units for which reproduction invariably leads to an unsuccessful target text. After all, it can be hypothesised, for example, that errors are more likely to occur with creative shifts for at least two reasons. Firstly, there is the risk of undue semantic changes, especially with concretisations. This is often observed with concretisations that run the risk of overspecifications. The following translation from an instructional text from the TransComp corpus (see Göpferich, Bayer-Hohenwarter et al. 2011) illustrates this:

ST: Check that control switch D is in position 0, then insert the attachments (i.e., Dough hook A as indicated).

TT: Ein-Aus-Schalter D (t8_ Prof_AIR)

The TT exemplifies a concretisation that unduly specifies the type of switch, because the control switch on the mixer that is described does not only serve the purpose of switching the device on and off, but also to select the mixing speed.

Secondly, errors are more likely to occur with creative shifts because they can be assumed to drain cognitive resources and lead to slips of attention that result in errors not directly connected to the shift as such. With reproductions, however, the error potential mainly seems to be connected to unidiomaticity and interferences, error categories that presumably are infrequently observed with professionals. 


\subsection{Synthesis}

The results presented in the previous sections are in some ways unexpected. Nevertheless, even without further analyses, there is a plausible explanation for the seemingly incongruent results: Successful translation performance is perhaps not necessarily characterised by a higher proportion of creative shifts, but by reflected decisions on the use of reproductions versus creative shifts depending on the specific demands of a particular translation unit (see also Prassl 2010 on translators' decisionmaking processes). A good example is the behaviour of professional $\mathrm{RCH}$, who proved to be capable of producing creative shifts and satisficing ${ }^{7}$ with literal reproduction as required. This idea of a "creativity-routine balance" is taken into account by BayerHohenwarter's (2010) creativity concept that does not focus on flexibility and originality alone, but on a cognitively economic balance between flexibility (evident e.g., in creative shifts) and fluency (evident e.g., in reproductions) against the background of acceptability. Without the fundamental ability to produce creative shifts, if necessary, the elaboration of acceptable target texts according to deliberate and reflected decision may suffer. It is possible, though, that the ability to produce creative shifts is an innate ability whose development solely depends on factors such as the translator's self-concept or perceived external quality criteria, and that it does not necessarily need to be learned.

\section{Conclusions and outlook}

In the analyses of group performance, it was found that the professionals used almost twice as many creative shifts as the $1^{\text {st }}$-semester students, but that the $3^{\text {rd }}$-semester students, on average, produced slightly more creative shifts than the professionals. This latter trend was even more pronounced for the creativity units. This result only partially supports the assumption that professionals produce more creative shifts (A2) and contradicts the assumption that professionals produce more creative shifts with creativity units (A3).

The analyses of individual performance revealed a considerable amount of interindividual differences but pointed to a fairly low correlation between creative performance and successful performance. This contradicts the assumption that translators who produce more creative shifts achieve higher-quality results (A1).

A closer look at the relationship between creativity and acceptability showed a similarity of trends for both variables. This seems to support A1. A detailed analysis into the quality and creative character of the 256 units again seemed to support A1 because the characteristics of $61 \%$ of the units were in line with my assumptions. From the 81 creative shifts that represented an unsuccessful translation, $67 \%$ were produced by the students.

These seemingly incongruent results can probably be explained by the notion of a "creativity-routine balance." It is not a high proportion of creative shifts that counts, but the ability to decide efficiently when to use a creative shift and when a mere reproduction is sufficient. Whereas the production of creative shifts is deemed to require more cognitive effort at least with less experienced translators and is expected to involve well-reflected decisions, the production of mere reproductions can be assumed to be a time-saving routine activity that involves less reasoning, is perceived 
as risk-avoiding by many translators and hence contributes to saving attentional resources. Students in their first semesters, and especially novices, can be expected to need much attention to understand the ST, clarify vocabulary issues, devise search strategies and solve mother tongue related issues such as spelling, and can thus be expected to have less attentional resources left for higher-order creative problemsolving. Also, they lack problem-sensitivity and show unreflected and dangerous "creativity," i.e., they run a higher risk of producing shifts that unduly change the intended ST message. In contrast to the more inexperienced translators, my analyses reveal that the more proficient translators show an increasing ability to apply creative shifts where necessary and appropriate and stick with effort-saving reproductions in cases where this leads to acceptable results. This can explain the high success of the professionals and modest performance of the $1^{\text {st }}$-semester students and the lack of congruency between translation success and creativity on the level of the individual translators alike.

From a methodological viewpoint, the present investigation proves that solid quantitative research into translational creativity is possible and that Wilss' (1988) doubts appear unfounded in the $21^{\text {st }}$ century. Even if this analysis of creative shifts only focuses on one single aspect of translational creativity, it shows that, by using this approach as a blueprint, comprehensive quantitative results can be obtained that allow for tracing translational creativity over time. It is argued that complex phenomena such as translational creativity, text difficulty or translational routine, that have so far escaped the scrutiny of translational research for methodological reasons, can be approached by meticulously defining and analysing a range of indicators that are believed to make up such a complex construct. The analysis of creative shifts is therefore a case in point and analyses of this type are carried out through my creativity assessment procedure which comprises a set of indicators assigned to key dimensions of translational creativity (see Bayer-Hohenwarter 2010). Exploratory analyses of complex psychological constructs such as the one presented in this article seem to be a reasonable first step towards identifying what indicators are central for the reliable measurement of a particular concept and can prepare avenues for investigation in larger-scale interdisciplinary studies using more reliable but also more costly methods, such as neuro-scientific methods (electroencephalography [EEG], functional magnetic resonance imaging [fMRI], magnetoencephalography [MEG]) in triangulation with psycholinguistic methods such as key-logging, eye-tracking, thinking aloud and screen recording used in translation process research. Such neuro-scientific investigations based on test items drawn from the existing analyses could venture to test the cognitive effort measured e.g., in terms of EEG power invested in the translation of creativity units and routine units, in the production of reproductions versus creative shifts and specific brain patterns characteristic of these experimental settings, particular groups of translators (novices vs. professionals) or certain individual translators. Eventually, if consistent patterns are found in individuals with a high tendency to produce creative shifts or if the triangulation of psycholinguistic and neuroscientific measurement methods yields correlations, it could one day become possible to reliably measure the creativity potential of particular translation tasks or individuate creative translators from a larger population. 


\section{ACKNOWLEDGMENTS}

I would like to thank Susanne Göpferich, Friederike Prassl, my proofreaders, the anonymous reviewers and the editors, whose feedback was greatly appreciated. My thanks also go to my husband who provided valuable help in mathematical matters.

\section{NOTES}

* Institut für Theoretische und Angewandte Translationswissenschaft. The research presented in this article forms part of the TransComp project led by Susanne Göpferich, for which support by the Austrian Science Fund (FWF) is acknowledged (project No. P20908-G03, September 2008August 2011).

1. Light-verb constructions such as "take a decision" refer to structures in which the light verb, e.g., "take," codes the verbal grammatical categories and the inner complement, e.g., "decision," provides most of the semantic content.

2. My assumption that translating literally is cognitively less effortful than abstractions, etc., is further backed by Brown's (1958) findings on the cognitive development of children (see Bayer-Hohenwarter 2010). This assumption, as valid as it may appear for every practising translator and scholar alike, ideally requires neurolinguistic testing.

3. See the document Mitteilungsblatt der Karl-Franzens-Universität Graz. 73. Sondernummer, 42c. Published on 15 February 2009. <https://online.uni-graz.at/kfu_online/wbMitteilungsblaetter. display?pNr =132015>, visited on 17 November 2011.

4. See Hayakawa, Samuel I. (1963): Symbol, Status, and Personality. $7^{\text {th }}$ ed. San Diego/New York/ London: Harvest HBJ.

5. See data documentation at http://gams.uni-graz.at/fedora/get/container:tc/bdef:Container/get.

6. The complete data documentation is available on the TransComp website (http://gams.uni-graz. at/fedora/get/container:tc/bdef:Container/get, visited on 13 July 2011), the Excel calculation sheets are available on request (ger1676@yahoo.com).

7. Satisfice is a psychological term referring to a decision-making strategy that does not aim at finding an optimal, but a barely acceptable solution.

\section{REFERENCES}

Adamczuk, Marzena (2005): Task-specific creativity in simultaneous interpreting. Doctoral thesis, unpublished. Vienna: University of Vienna.

Al-sнавав, Omar, Sheikh (1996): Interpretation and the Language of Translation. Creativity and Convention in Translation. London: Janus.

AUdET, Louise (2008): Évaluation de la traduction littéraire: de la «sensibilité à la littérarité» à la «littérarité en traduction». TTR. 21(1):127-172.

Audet, Louise and Dancette, Jeanne (2005): Le mouvement de la création dans la traduction littéraire. Bulletin suisse de linguistique appliquée. 81:5-24.

Ballard, Michel (1997): Créativité et traduction. Target. 9(1):85-110.

Bastin, Georges (2000): Evaluating Beginners' Re-expression and Creativity: A Positive Approach. The Translator. 6(2):231-245.

Bastin, Georges (2003): Aventures et mésaventures de la créativité chez les débutants. Meta. 48(3):347-360.

Bastin, Georges and Betancourt, Miguel (2005): Les avatars de la créativité chez les traducteurs débutants. In: Jean Peeters, ed. On the Relationships between Translation Theory and Translation Practice. Studien zur romanischen Sprachwissenschaft und interkulturellen Kommunikation. Vol. 19. Frankfurt am Main: Peter Lang, 213-224.

Bayer-Hohenwarter, Gerrit (2009): Translational creativity: how to measure the unmeasurable. In: Susanne Göpferich, Arnt Lykke Jakobsen and Inger Mees, eds. Behind the Mind: Methods, Models and Results in Translation Process Research. Copenhagen Studies in Language. Vol. 37. Copenhagen: Samfundslitteratur, 39-59.

BAYER-HOHENWARTER, Gerrit (2010): Comparing translational creativity scores of students and professionals: flexible problem-solving and/or fluent routine behaviour? In: Susanne 
GöPferich, Fabio Alves and Inger Mees, eds. New Approaches in Translation Process Research. Copenhagen Studies in Language. Vol. 39. Copenhagen: Samfundslitteratur, 83-111.

Brown, Roger (1958): How Shall a Thing be Called? Psychological Review. 65:14-21.

BYrne, Jody (2006): Suppression as a form of creativity in technical translation. In: Ian Kemble and Carol O'Sullivan, eds. Proceedings of the Conference held on 12th November 2005 in Portsmouth. Portsmouth: University of Portsmouth, 6-13.

Chaume Varela, Frederic (1998): Textual Constraints and the Translator's Creativity in Dubbing. In: Ann Beylard-Ozeroff, Jana Králová and Barbara Moser-Mercer, eds. Translator's Strategies and Creativity. Amsterdam/Philadelphia: John Benjamins, 15-22.

Сно, Sang-Eun (2006): Translator's Creativity found in the Process of Japanese-Korean Translation. Meta. 51(2):378-388.

Dancette, Jeanne, Audet, Louise and Jay-Rayon, Laurence (2007): Axes et critères de la créativité en traduction. Meta. 52(1):108-122.

De Beaugrande, Robert (1978): Factors in a theory of poetic translating. Approaches to Translation Studies. Vol. 5. Assen: Van Gorcum.

Durieux, Christine (1991): Liberté et créativité en traduction technique. In: Marianne Lederer and Fortunato Israel, eds. La liberté en traduction. Actes du colloque international tenu à l'E.S.I.T. les 7, 8 et 9 juin 1990 réunis par Marianne Lederer. Paris: Didier Erudition, 169-179.

Englund Dimitrova, Birgitta (2005): Expertise and Explicitation in the Translation Process. Amsterdam/Philadelphia: John Benjamins.

Fontanet, Mathilde (2005): Temps de créativité en traduction. Meta. 50(2):432-447.

Fontcuberta Gel, Joan (1997): Creatividad en la traducción audiovisual. In: Purificación Fernandéz Nistal and José María Bravo Gozalo, eds. Aproximaciones a los Estudios de Traducción. Valladolid: Servicio de Apoyo a la Enseñanza, 217-230.

Forstner, Martin (2005): Bemerkungen zu Kreativität und Expertise. Lebende Sprachen. 50(3):98-104.

GöpfERICH, Susanne (2009): Towards a model of translation competence and its acquisition: the longitudinal study TransComp. In: Susanne Göpferich, Arnt Lykke Jakobsen and Inger Mees, eds. Behind the Mind: Methods, Models and Results in Translation Process Research. Copenhagen Studies in Language. Vol. 37. Copenhagen: Samfundslitteratur, 11-37.

GöPfERICH, Susanne (2010a): The translation of instructive texts from a cognitive perspective: novices and professionals compared. In: Susanne GöPferich, Fabio Alves and Inger M. Mees, eds. New Approaches in Translation Process Research. Copenhagen Studies in Language. Vol. 39. Copenhagen: Samfundslitteratur, 5-57.

GÖPFERICH, Susanne (2010b): Anleitungen rezipieren, Anleitungen produzieren: Empirische Befunde zu kognitiven Prozessen bei Übersetzungsnovizen und Übersetzungsprofis. Hermes. 44:169-197.

Göpferich, Susanne, Bayer-Hohenwarter, Gerrit and Stigler, Hubert, eds. (2011): TransComp - The Development of Translation Competence. Corpus and asset management system for the longitudinal study TransComp. Graz: University of Graz. Visited on 12 January 2010, <http://gams.uni-graz.at/container:tc $>$.

Göpferich, Susanne, Bayer-Hohenwarter, Gerrit, Prassl, Friederike et al. (2011): Exploring translation competence acquisition: Criteria of analysis put to the test. In: Sharon O'BRIEN, ed. Cognitive Explorations of Translation. New York/London: Continuum, 57-85.

Guilford, Joy Paul (1950): Creativity. In: American Psychologist. 5: 444-454.

Hague, Daryl R. (2009): Prophets and Pandemonium: creativity in the translating self. In: Phrae Chittiphalangsri, Sue-Ann Harding et Dorothea Martens, eds. New Voices in Translation Studies. 5:16-28.

Heiden, Tanja (2005): Blick in die Black Box: Kreative Momente im Übersetzungsprozess: eine experimentelle Studie mit Translog. Meta. 50(2):448-472.

Hubscher-Davidson, Séverine (2005): Psycholinguistic Similarities and Differences between Subjects as Seen Through TAPS. International Journal of Translation. 17(1-2):97-107. 
Hubscher-DAvidson, Séverine (2006): Using TAPs to analyse creativity in translation. In: Ian Kemble and Carol O'Sullivan, eds. Proceedings of the Conference held on 12th November 2005 in Portsmouth. Portsmouth: University of Portsmouth, 63-71.

Ivir, Vladimir (1998): Linguistic and Communicative Constraints on Borrowing and Literal Translation. In: Ann Beylard-Ozeroff, Jana Králová and Barbara Moser-Mercer, eds. Translator's Strategies and Creativity. Selected papers from the 9th international conference on translation and interpreting. (Prague, September 1995). Amsterdam/Philadelphia: John Benjamins, 137-144.

Jettmarová, Zuzana (1998): Literalness as an Overall Strategy for Translating Advertisements in the Czech Republic. In: Ann Beylard-Ozeroff, Jana Králová and Barbara MoserMerCer, eds. Translator's Strategies and Creativity. Selected papers from the 9th international conference on translation and interpreting. (Prague, September 1995). Amsterdam/ Philadelphia: John Benjamins, 97-105.

Jones, Francis R. (2006): Unlocking the black box: researching poetry translation processes. In: Manuela Perteghella and Eugenia Loffredi, eds. Translation and Creativity. Perspectives on Creative Writing and Translation Studies. London/New York: Continuum, 59-74.

KAINDL, Klaus (2005): Kreativität in der Übersetzung von Popularmusik. Lebende Sprachen. 50(3):119-124.

Kemble, Ian and O'Sullivan, Carol, eds. (2006): Proceedings of the Conference held on 12th November 2005 in Portsmouth. Portsmouth: University of Portsmouth.

Kenny, Dorothy (2000): Lexical Hide-and-Seek: Looking for Creativity in a Parallel Corpus. In: Maeve OlOHAN, ed. Intercultural faultlines: textual and cognitive aspects. Research models in translation studies. Vol. 1. Manchester: St. Jerome, 93-104.

Kenny, Dorothy (2001): Lexis and Creativity in Translation. A Corpus-based Study. Manchester/ Northampton: St. Jerome.

Kenny, Dorothy (2006): Creativity in translation: opening up the corpus-based approach. In: Ian Kemble and Carol O'Sullivan, eds. Proceedings of the Conference held on 12th November 2005 in Portsmouth. Portsmouth: University of Portsmouth, 72-81.

Kussmaul, Paul (1991): Creativity in the Translation Process: Empirical Approaches. In: Kitty M. van Leuven-Zwart and Ton Naaijkens, eds. Translation Studies: The State of the Art. Proceedings of the First James S. Holmes Symposium on Translation Studies. Approaches to translation studies 9. Amsterdam/Atlanta: Rodopi, 91-101.

Kussmaul, Paul (1993): Empirische Grundlagen einer Übersetzungsdidaktik: Kreativität im Übersetzungsprozeß. In: Justa Holz-Mänttäri and Christiane Nord, eds. Traducere Navem. Festschrift für Katharina Reiß zum 70. Geburtstag. Tampere: Tampereen yliopisto, 275-286.

Kussmaul, Paul (1997): Die Rolle der Psycholinguistik und der Kreativitätsforschung bei der Untersuchung des Übersetzungsprozesses. In: Eberhard Fleischmann, Wladimir Kutz and Peter A. Sснмітт, eds. Translationsdidaktik. Grundfragen der Übersetzungswissenschaft. Tübingen: Narr, 605-611.

Kussmaul, Paul (1998): Kreativität. In: Mary Snell-Hornby, Hans G. Hönig, Paul Kussmaul et al., eds. Handbuch Translation. Tübingen: Stauffenburg, 178-180.

Kussmaul, Paul (1999): Die Übersetzung als kreatives Produkt. In: Alberto Gil, Johann Haller, Erich Steiner et al., eds. Modelle der Translation. Grundlagen für Methodik, Bewertung, Computermodellierung. Frankfurt/Main: Peter Lang, 177-189.

Kussmaul, Paul (2000a): Gedankensprünge beim Übersetzen. In: Mira Kadric, Klaus KaIndL and Franz PöchHACKer, eds. Translationswissenschaft. Festschrift für Mary Snell-Hornby zum 60. Geburtstag. Tübingen: Stauffenburg, 305-317.

Kussmaul, Paul (2000b): A Cognitive Framework for Looking at Creative Mental Processes. In: Maeve OlOHAn, ed. Intercultural faultlines: textual and cognitive aspects. Research models in translation studies, 1. Manchester: St. Jerome, 57-71.

Kussmaul, Paul (2000c): Types of creative translating. In: Andrew Chesterman, Natividad Gallardo San Salvador and Yves Gambier, eds. Translation in Context. Selected Papers 
from the EST Congress, Granada 1998. Benjamins translation library. Vol. 39. Amsterdam: Benjamins, 117-126.

Kussmaul, Paul (2004): Translation als kreativer Prozess - ein kognitionslinguistischer Erklärungsversuch. In: Lew N. Zyватоw, ed. Translation in der globalen Welt und neue Wege in der Sprach- und Übersetzerausbildung. Frankfurt am Main: Peter Lang, 93-116.

Kussmaul, Paul (2005): Translation through Visualization. Meta. 50(2):378-391.

Kussmaul, Paul (2007a): Kreatives Übersetzen. Studien zur Translation. Vol. 10. Tübingen: Stauffenburg.

Kussmaul, Paul (2007b): Verstehen und Übersetzen. Ein Lehr- und Arbeitsbuch. Tübingen: Narr.

LAVIOSA, Sara (1998): Core patterns of lexical use in comparable corpus of English narrative prose. Meta. 43(4):557-570.

Lee-Jahnke, Hannelore (2005): Unterrichts- und Evaluierungsmethoden zur Förderung des kreativen Übersetzens. Lebende Sprachen. 50(3):125-132.

Mackenzie, Rosemary (1998): Creative Problem-Solving and Translator Training. In: Ann Beylard-Ozeroff, Jana Králová and Barbara Moser-Mercer, eds. Translator's Strategies and Creativity. Selected papers from the 9 th international conference on translation and interpreting. (Prague, September 1995). Amsterdam/Philadelphia: John Benjamins, 201-206.

NidA, Eugene A. (1998): Translators' Creativity versus Sociolinguistic Constraints. In: Ann Beylard-Ozeroff, Jana Králová and Barbara Moser-Mercer, eds. Translator's Strategies and Creativity. Selected papers from the 9 th international conference on translation and interpreting. (Prague, September 1995). Amsterdam/Philadelphia: John Benjamins, 127-136.

Nord, Christiane (2005): Kreativität und Methode - spannende oder gespannte Beziehung? Lebende Sprachen. 50(3):137-141.

Pellatt, Valerie (2006): The ASPRO model of creativity: assessing the creative handling of the translation of 'fat' and 'old.' In: Ian Kemble and Carol O'Sullivan, eds. Proceedings of the Conference held on 12th November 2005 in Portsmouth. Portsmouth: University of Portsmouth, 52-62.

PisArska, Alicja (1989): Creativity of Translators - The Translation of Metaphorical Expressions in Non-Literary Texts. Poznań: UAM.

Pommer, Sieglinde E. (2008): No creativity in legal translation? Babel. 54(4):355-368.

Prassl, Friederike (2010): Translators' decision-making processes in research and knowledge integration. In: Susanne Göpferich, Fabio Alves and Inger Mees, eds. New Approaches in Translation Process Research. Copenhagen Studies in Language. Vol. 39. Copenhagen: Samfundslitteratur, 57-81.

Quillard, Geneviève (1998): Translating Advertisements and Creativity. In: Ann BeylardOzeroff, Jana Královí and Barbara Moser-Mercer, eds. Translator's Strategies and Creativity. Selected papers from the 9 th international conference on translation and interpreting. (Prague, September 1995). Amsterdam/Philadelphia: John Benjamins, 23-31.

Quillard, Geneviève (2001): La traduction des jeux de mots dans les annonces publicitaires. TTR. 14(1):117-157.

RiCCARdi, Alessandra (1998): Interpreting strategies and creativity. In: Ann BEyLARD-Ozeroff, Jana Králová, Barbara Moser-Mercer, eds. Translator's Strategies and Creativity. Selected papers from the 9th international conference on translation and interpreting, Prague, September 1995. Amsterdam/Philadelphia: John Benjamins, 171-179.

ŠARČEviĆ, Susan (2000): Creativity in legal translation: how much is too much? In: Andrew Chesterman, Natividad Gallardo San Salvador and Yves Gambier, eds. Translation in Context. Selected Papers from the EST Congress, Granada 1998. Benjamins translation library. Vol. 39. Amsterdam/Philadelphia: John Benjamins, 281-291.

Sснмiтt, Peter Axel (2005): Grenzen der Kreativität. Lebende Sprachen. 50(3):104-111.

STEWART, Dominic (2000): Conventionality, creativity and translated text: The implications of electronic corpora in translation. In: Maeve Olohan, ed. Intercultural Faultlines: Textual and Cognitive Aspects 1: Research Models in Translation Studies. Manchester: St. Jerome, 73-91. 
Тномӓ, Sandra (2003): Creativity in Translation. An Interdisciplinary Approach. Doctoral thesis, unpublished. Salzburg: University of Salzburg.

Tirkkonen-Condit, Sonja; Mäkisalo, Jukka and Immonen, Sini (2008): The translation process - interplay between literal rendering and a search for sense. Across Languages and Cultures. 9(1):1-15.

WildE, Ursula (1994): Werbesprache - zwischen Kreativität und Fachsprachlichkeit. Analyse einiger Beispiele aus dem Französischen. Fachsprache. 15(1-2):18-26.

Wilss, Wolfram (1988): Kognition und Übersetzen: zu Theorie und Praxis des menschlichen und des maschinellen Übersetzens. Tübingen: Niemeyer.

ZHong, Yong (2005): A Matter of Principles: Empirical Treatments of Translation Principles - A Case Study. Meta. 50(2):495-510. 